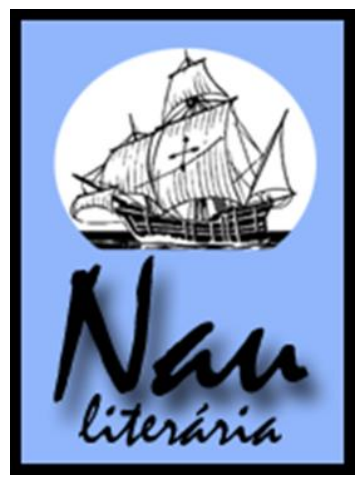

Nau Literária: crítica e teoria de literaturas • seer.ufrgs.br/NauLiteraria ISSN 1981-4526 • PPG-LET-UFRGS • Porto Alegre • Vol. 10 N. $2 \bullet$ jul/dez 2014

Dossiê: Migração, exílio e identidade

\title{
Exílio e Identidade: A reconstrução dos símbolos nacionais em Almeida Garrett
}

\section{Nuno Miguel de Brito e Souza Teixeira*}

\begin{abstract}
Resumo: O objetivo deste trabalho é mostrar o exílio enquanto processo de afastamento forçado que reforça a idealização da nacionalidade e dos seus símbolos. O estudo recai essencialmente sobre o poema Camões de Almeida Garrett (Paris, 1825).
\end{abstract}

Palavras-chave: Exílio; Almeida Garrett; Camões; Romantismo.

\begin{abstract}
The aim of this study is to show the exile as A forced separation that reinforces the idealization of the nationality and their symbols. This study focuses, essentially, on Camões poem by Almeida Garrett (Paris, 1825).
\end{abstract}

Keywords: Exile; Almeida Garrett; Camões; Romanticism.

\section{Nacionalismo e Historicismo}

A característica nuclearmente distintiva do Romantismo Literário Português é a valorização da Nacionalidade, atitude que, embora sendo geral em todo o percurso romântico internacional, no caso português se expressou com maior incidência, sendo dotado de uma especificidade própria e um contexto específico no qual os fenómenos de exílio e a instabilidade política constituíram um elemento chave.

O nacionalismo literário é uma atitude geral em todos os espaços tocados pelo Romantismo, determinado sobretudo pela resistência ao peso do Classicismo greco-latino, mas também por uma oposição contra os centros polarizadores de cultura ocidental. Este último fator é essencial para o caso português, enquanto periferia geográfica destes núcleos. $\mathrm{O}$ Romantismo Português insurge-se contra o Francesismo e contra os Afrancesados, numa atitude de afirmação da nacionalidade, não tanto enquanto limite político unitário, mas sim como exaltação mitificante de uma comunidade nacional e idealização épica de um povo. Em 1835 Alexandre Herculano afirma na revista Repositório Literário "Diremos somente que somos românticos, querendo que os portugueses voltem a uma Literatura sua [...], que amem a Pátria, mesmo que em poesia" (HERCULANO, 1898, p. 69), afirmação de um percurso romântico especificamente português que assuma a procura de uma identidade representativa da essência popular, que condense e espelhe um verdadeiro imaginário étnico nacional:

\footnotetext{
* Doutorando em Estudos Literários Culturais e Interartísticos pela Faculdade de Letras da Universidade do Porto, Professor de Literatura Portuguesa em Facultad de Filosofía y Letras / Universidad Nacional Autónoma de México (UNAM) Licenciatura de Línguas e Literaturas Modernas - Letras Portuguesas.
} 
valorização do Nosso em relação ao Estrangeiro que é também a afirmação da construção mitificante do Passado em face de um Presente instável.

Essa procura encontra as suas raízes unitárias no período medieval, momento histórico de criação da nacionalidade, momento reconstruído, idealizado e restaurado. É de salientar, como especificidade própria da primeira geração romântica portuguesa, a valorização do cristianismo enquanto resistência ao excesso mitológico greco-latino dos autores neoclássicos da Arcádia Lusitana. Os mitos cristãos amplamente tratados em Alexandre Herculano e Almeida Garrett aparecem fortalecidos nos relatos dos milagres de Santa Iria e de Santarém das Viagens na Minha Terra e na fusão do imaginário religioso com os mitos históricos ligados ao início da nacionalidade através do milagre de Ourique, constantemente tratado na recriação histórica ficcional de Alexandre Herculano. Trata-se de substituir uma mitologia clássica, erudita e fechada (dominada por uma elite academizada) por uma mitologia nacional aberta (conhecida de todos) que fixe e documente o maravilhoso popular.

Fora da esfera literária é interessante notar que o século XIX é por excelência o tempo edificante dos mitos nacionais, de uma propaganda étnica nacionalista que serve interesses políticos concretos de manipulação da Histórica, canalizando-a para a sua própria justificação. Tempo de fortalecimento de uma retórica nacionalista que lança a proposta de que "Os povos europeus são unidades sociais e culturais distintas, estáveis e objetivamente identificáveis" (GEARY, 2008, p.19). Segundo Patrick J. Geary os estados atuais enquanto "comunidades imaginadas" foram impulsionados por intelectuais e políticos do século XIX que "transformaram tradições nacionalistas românticas, mais antigas, em programas políticos" (GEARY, 2008, p.24) fortalecendo o sentimento de pertença a um país (mais do que a uma simples unidade política). O surgimento dos hinos nacionais, de uma iconografia própria e a construção de símbolos comunitários das diferentes nações cumprem essa finalidade. Entre vários exemplos Patrick Geary refere em O Mito das Nações: A Invenção do Nacionalismo casos específicos, tais como, a ampla difusão cultural do uso do Kilt escocês (pouco conhecido até então a não ser em pequenas regiões montanhosas) ou a rápida divulgação da lenda de Guilherme Tell na Suíça, construção de um passado unificador que fortaleça um sentimento de pertença a uma unidade cultural e social distinta.

Se bem que o nacionalismo literário romântico coexista temporalmente com esta atitude parcial ou fortemente fabricada, ele vive à margem dela, brota de um desejo autêntico de restaurar e trazer de novo à superfície a verdadeira (enquanto popular) identidade nacional. Não serve uma finalidade política concreta e manifesta-se desiludida com o Presente histórico. 
As raízes e as tradições populares que no caso francês encontram a sua expressão em A Feiticeira de Michelet, ou em Nossa Senhora de Paris de Victor Hugo, são as temáticas centrais destes romances históricos cujo trama se desenvolve na Idade Média, período que o Humanismo e o Neoclassicismo Literários tinham desvalorizado. O gosto pelas tradições medievais, de que o Romantismo se nutre em todas as suas manifestações culturais, é ainda mais evidente em países integrados durante bastante tempo em monarquias estrangeiras ou dominados temporariamente pelas forças napoleónicas. Neste contexto, a Idade Média é vista como o tempo da criação das nações que se formam com a fragmentação do Império Romano. Para Alexandre Herculano e Almeida Garrett a Idade Média é a época nacional e popular por excelência. Reconstruir esse passado, através da Literatura e da Arte é também tornar palpável uma identidade nacional. Na arquitetura o estilo neogótico reproduz os modelos das grandes catedrais, na música o gosto romântico centra-se no folclore, a ópera passa a narrar lendas medievais (por exemplo, Tristão e Isolda). A recriação literária deste período, um tempo de superstição, magia, ruínas góticas, milagres e lendas é propagada também nas recolhas de literatura de tradição oral popular. No norte da Europa a poesia integra lendas célticas e germânicas. Walter Scott descreve nos seus romances históricos a luta ancestral dos clãs escoceses contra o domínio inglês e entre 1802 e 1803 publica Os Cantos da Fronteira Escocesa ${ }^{1}$. Na Alemanha são publicados pelos Irmãos Grimm os dois volumes das Lendas Alemãs (1816-1818) e em Espanha os cinco volumes do Romancero General de Agustín Durán (1828 e 1843).

Seguindo esta tendência geral, Almeida Garrett publica em 1843 o primeiro volume do Romanceiro e Cancioneiro Geral. Os volumes II e III são publicados em 1851. O seu projeto de restaurar uma autêntica literatura popular de expressão oral portuguesa só é suspenso com a sua morte três anos depois, forjando-se como um autêntico projeto de vida, cujas primeiras pesquisas foram começadas em 1825 durante o período de exílio ${ }^{2}$. Em 1828 é publicado em Londres Adozinda, texto que abrirá o primeiro volume do Romanceiro. Na introdução Garrett reforça que:

\footnotetext{
${ }^{1}$ texto que serve de modelo a Garrett, sendo citado várias vezes nos textos introdutórios dos diferentes volumes do Romanceiro e Cancioneiro Geral.

${ }^{2}$ Em 2004 foi anunciada a descoberta de uma coleção de manuscritos autógrafos do autor com esboços e textos não completos que integrariam a continuação do Romanceiro e Cancioneiro Geral. Manuscritos integrados no arquivo particular Futscher Pereira. Um estudo profundo destes manuscritos pode ser encontrado em BOTTO, Sandra Cristina de Jesus, As Fontes do Romanceiro de Almeida Garrett. Uma proposta de "edição crítica", Lisboa, Faculdade de Ciências Sociais e Humanas da Universidade de Lisboa, 2011. Tese de Doutoramento em Línguas, Literaturas e Culturas, disponível em http://run.unl.pt/handle/10362/7205. (acesso em30-08-2014).
} 
O que é preciso é estudar as nossas primitivas fontes poéticas, os romances em verso e as legendas em prosa, as fábulas e crenças velhas, as costumeiras e as superstições antigas [...]. O tom e o espírito verdadeiramente português, esse é forçoso estudá-lo no grande livro nacional que é o povo, e as suas tradições e as suas virtudes, e os seus vícios e os seus erros. (LÓPES; SARAIVA, 2008, p.683)

Almeida Garrett assume, assim, como objetivo determinante do Cancioneiro "suprir uma grande falta na nossa Litteratura com o trabalho que intentei nesta colecção", (GARRETT, 1963, p.4) ao "Reunir e restaurar, com este intuito, as canções populares, xácaras, romances ou rimances, solaus, ou como lhe queiram chamar, é um dos primeiros trabalhos, que precisávamos. É o que eu fiz - é o que eu quis fazer.” (GARRETT, 1963, p.7). Esta tendência geral para os trabalhos de recolha das raízes literárias fundadoras das nacionalidades, documentação e fixação de um património cultural que é necessário restaurar é contemplada também por um interesse historiográfico de grande projeção no período medieval. Não é por acaso que alguns dos autores determinantes do Romantismo inicial são historiadores que focalizaram os seus estudos historiográficos no período medieval. Michelet em França, Alexandre Herculano em Portugal e Walter Scott na Escócia conciliaram a criação literária com a investigação historiográfica deste período. A recolha de documentação medieval que Alexandre Herculano efetuou enquanto Diretor das Bibliotecas Reais da Necessidades e da Ajuda, Bibliotecário Real, ou ainda organizador da Biblioteca Pública do Porto, com os fundos retirados das bibliotecas monásticas e miguelistas, foi de vital importância para a Ciência Histórica Portuguesa. Em 1851 publica os dois volumes das Lendas e Narrativas e concilia a ficção e a investigação históricas com a recolha documental de Literatura Oral.

\section{Exílio}

A adesão de Almeida Garrett e Alexandre Herculano à causa liberal levou-os por mais de uma vez ao exílio. À Revolução de 1820 que possibilitou a implementação da primeira Constituição Portuguesa sucedeu, em 1823, um contragolpe das forças absolutistas lideradas por D. Miguel, a Vila-Francada, que terminou com a primeira experiência liberal portuguesa. Grande parte dos Liberais vêem-se, então, forçados a sair do país. A morte de D. João VI em 1826 e a nomeação de D. Pedro IV como seu sucessor permitiu o regresso a Portugal dos liberais exilados, mas dois anos depois é restaurado o Poder por D. Miguel que põe fim à Carta Constitucional outorgada por D. Pedro. Dá-se então uma segunda vaga de exílio de grande parte dos liberais, que planeiam no estrangeiro a recuperação do poder ao lado de D. Pedro. Em 1832 o exército de D. Pedro e os liberais no exílio encontram-se para efetuarem o 
desembarque do Mindelo, operação militar que culmina com a ocupação do Porto. Com eles vem Almeida Garrett que durante esse período se tinha fixado em Inglaterra e em França.

Estas migrações forçadas, impostas pelos constrangimentos políticos de um tempo grandemente conturbado, são ao mesmo tempo migrações culturais que proporcionaram tanto a Garrett como a Herculano um contacto mais profundo e abrangente com os autores do Romantismo inglês e francês. Como cônsul-geral em Bruxelas Almeida Garrett teve oportunidade de um contacto mais direto com Goethe e Schiller na sua língua original.

Almeida Garrett, durante a sua primeira experiência de exílio (1824-1826), fixou-se em França, depois de um curto período de residência em Inglaterra. Em França viveu primeiro em Havre, cidade portuária na foz do rio Sena e depois em Paris onde escreveu e publicou os poemas narrativos Camões (1825) e Dona Branca (1826). É unânime aceitar a publicação, em Paris, do poema Camões como o marco temporal que inicia o Romantismo Literário em Portugal (1825).

O poema está dividido em 10 Cantos, reproduzindo na sua estrutura Os Lusíadas, e introduz a versificação livre e uma maior liberdade formal. Narra a vida de Camões, centrando-se, no tempo em que este escreveu de Os Lusíadas, na sua receção, no regresso a Portugal e nas condições de precariedade e miséria que o poeta enfrentou nos seus últimos anos de vida ao sobreviver de esmolas e da proteção da igreja juntamente com o escravo Jau, o amigo fiel que o acompanhou desde o Oriente até Lisboa.

O Poema põe em evidência o choque entre a representação de Camões como símbolo nacional representativo de toda a Pátria e a sua figura enquanto pessoa histórica não dignificada à altura pelo país. O sentimento de ingratidão "Ingrata... ingrata Pátria! [...]" (GARRETT, 1984, p.60), "Vingar a afronta de uma Pátria ingrata" (GARRETT, 1984, p.58) alia-se à deceção provocada pela falta de um reconhecimento justo e dignificante. Sentimento continuamente invocado e fortalecido nos diálogos que Camões estabelece, enquanto personagem, com o seu amigo Jau. Diálogos carregados de profecias e augúrios trágicos, numa visão e construção de negatividade antecipada, em jeito de prolepse, que se cumpre com o final simbólico: o momento da morte de Camões que é a morte da Pátria: "Os olhos turvos para o Céu levantam; / E já no arranco extremo: - Pátria, ao menos / juntos morremos... - E expirou coa Pátria.” (GARRETT, 1984, p.157). Enquanto personagem do poema narrativo de Almeida Garrett, Camões aparece como símbolo expansivo de toda a comunidade nacional, evidência de um passado sublime que o país Presente não iguala. Símbolo totalizante de um passado que o país não cumpre, um tempo que o país não corresponde. Podemos encontrar a mesma construção alegórica em Viagens na Minha Terra, quando o narrador regressa de 
Santarém a Lisboa “- Santarém também morreu; e morreu Portugal” (GARRETT, 1984, p. 333), este Santarém morto é o resultado de uma reflexão que Almeida Garrett estabelece sobre o passado fundacional de Portugal, Santarém, como a cidade que D. Afonso Henriques conquistou aos mouros e tornou capital do reino. À cidade de Santarém o autor atribui, então, o mesmo grau de idealidade de Camões, a grandiosidade de um passado pela qual Almeida Garrett transmite uma deceção fulgurante face ao Presente. A morte de Camões ou a morte de Santarém adquirem o mesmo significado trágico, a morte física ou as ruínas da cidade pelas quais o narrador das Viagens na Minha Terra se passeia. Manifesta-se nos dois casos uma construção idealizante dos símbolos nacionais. Nesse sentido em Camões, Almeida Garrett canta a desilusão e o afundamento lento da Pátria simulando a forma de uma anti epopeia trágica; pelo fim dos símbolos do país que são o fim do próprio país enquanto comunidade viva expressa toda a sua deceção face a um Presente nacional do qual se sente desapegado, desvinculado e forçosamente subtraído pelos condicionalismos do exílio. Deceção de não ver concretizados os esforços liberais com a luta do exílio numa sociedade mais igualitária que o Constitucionalismo Liberal prometia, mas sim, de constatar um estancamento do país fortemente debilitado pelo prolongamento da guerra civil e o aparecimento de uma sociedade que pouco se opunha às velhas instâncias de poder. Garrett expõe um paralelismo biográfico entre a sua vida e o percurso final de Luís Vaz de Camões através do sentimento de uma luta em vão (uma luta que a Pátria não cumpre, dignifica e continua) e um sentimento de perda que eleva a Saudade a elemento unificador de uma experiência de exílio. Enquanto personagem do poema narrativo, Camões representa uma transposição da vida do próprio Almeida Garrett, (um alter-ego e duplo seu) e de forma expansiva, de toda a luta liberal do seu tempo. Almeida Garrett transporta todo o poder simbólico do mito camoniano para o Presente.

\section{Destabilizando a Identidade}

O herói coletivo de Os Lusíadas (o povo português e mais especificamente os nautas envolvidos na expedição marítima de Vasco da Gama) é, também, transferido no poema épico de Almeida Garrett para um herói individual, o próprio autor de Os Lusíadas enquanto individuo histórico, não deixando o herói de representar um todo unitário nacional, não deixando nunca de representar um herói coletivo, toda uma comunidade mitificada. Garrett reforça a identificação com o autor de Os Lusíadas, enquanto desterrado da Pátria, abandonado por ela, num tempo de transformações sociais profundas "Perseguido no exílio imerecido", (GARRETT, 1984, p. 80), expressando o sentimento de esforço inecessário, 
esforço em vão. A experiência de migração forçada em França proporciona a Almeida Garrett um afastamento direto do país que é propício a uma mitificação da nacionalidade e dos seus símbolos abalado por sentimentos opostos, distanciamento imposto que potencia a sensação de perda, Saudade à volta da qual Garrett cria uma rede semântica omnipresente em todo o poema narrativo. Sentimentos de dor agudizada e transmitido de forma hiperbólica: "Saudade! Gosto amargo de infelizes, / Delicioso pungir de acerbo espinho, / Que me estás repassando, o íntimo peito / com dor que os seis d'alma dilacera [...] Corações que estalam, e gotejam / Não já sangue de vida, mas delgado / Soro de estanques lágrimas - Saudade" (GARRETT, 1984, p.17); exacerbação de uma corrente emocional eufórica, muitas vezes forçada em perífrases complexas, interjeições recorrentes, forte presença de pontuação subjetiva, imagens desfiguradas pelo excesso hiperbólico, mas que transporta, em todo o seu expoente, a dissolução da figura de Camões com o próprio conceito de nacionalidade, cruzamento inseparável em que ambos se confundem: "Viram do novo Homero o Canto insigne / Que à Pátria glório monumento augusto / Sublime erguia. Soa o brado ingente / Já pela Europa; e o nome lusitano / Ao nome de Camões eterno seu une" (GARRETT, 1984, p.143). Do Fascínio que Luís Vaz de Camões e Os Lusíadas exerceram sobre a personalidade literária de Almeida Garrett é completamente representativo o que ele escreve no capítulo VI de Viagens na Minha Terra: "Desde que me entendo, que leio, que admiro Os Lusíadas, enterneço-me, choro, ensoberbeço-me com a maior obra de engenho que ainda apareceu no Mundo, desde a Divina Comédia até ao Fausto..." (GARRETT, 1984, p.155). Para Eduardo Lourenço a força do símbolo camoniano e a sua representação em Garrett prende-se à materialização da saudade enquanto sentimento incomunicável de sofrimento e dor:

O poema Camões é o primeiro grande texto português tecido juntamente com o texto camoniano. Mas, à recuperação e à metamorfose do texto épico, Garrett dá um fundamento original, fazendo da palavra Saudade e do sentimento que ela exprime, sua verdadeira Musa. Em última análise, o próprio Camões é uma encarnação, entre outras, - mesmo que seja a mais sublime de todas - de um sentimento que o ultrapassa, e através do qual todos os portugueses compartilham a indizível mistura de sofrimento e dor, que se manifestam pela Saudade [...] Para Garrett, Camões representa menos o Poeta da Pátria, que o de sua ausência, quase de sua perda. Isso explica o motivo pelo qual seja sobre um pano de fundo de exílio, exílio da terra natal, assim como exílio do rosto amado, que explode, todo poderoso, um canto onde a Saudade encontra sua expressão mítica à sombra de Camões. Graças à conversão do jovem Garrett ao Romantismo, a presença camoniana no âmbito da cultura portuguesa assume uma nova significação. Não se trata apenas de uma presença entre outras, mas de um sinal de mudança, de uma espécie de revolução cultural que modifica profundamente os mecanismos de nosso imaginário. (LOURENÇO, 2001, p. 79)

A morte de Luís Vaz de Camões (1580) coexiste com a perda da independência portuguesa, com a incorporação do Reino de Portugal no Domínio da Coroa Espanhola. Nesse 
sentido, a ausência de Camões ultrapassa a sua própria figura. O seu poder simbólico alia-se com a Saudade, o mesmo sentimento de perda de identidade que o Exílio põe em evidência. A morte dos símbolos unitários da individualidade nacional é a morte da pátria porque com ela se confunde e cruza. O poder do símbolo camoniano centra-se então em algo inacessível, que não voltará e que não tocará o Presente, que se confunde com a própria saudade enquanto emoção indizível. Tal como no Sebastianismo, uma aparição de D. Sebastião terminaria para sempre com o mito, o mito de Camões representa-se, em toda a sua potência, pela ausência e sensação de perda que inaugura. A experiência emocional do exílio torna, assim, o mito mais palpável; o exílio destabiliza a identidade, introduz nele a nostalgia e solidão que o próprio Garrett apresenta nas notas ao Canto Primeiro do poema:

\begin{abstract}
Quase todo este poema foi escrito no verão de 1824 em Ingouville ao pé do Havre de Grace, na margem direita do Sena. Passei ali cerca de dois anos da minha primeira emigração, tão só e tão consumido, que a mesma distracção de escrever, o mesmo triste gosto que achava em recordar as desgraças do nosso grande Génio, me quebrava a saúde e destemperava mais os nervos. Fui obrigado a interromper o trabalho: e dei-me, como indicação higiénica, a composição menos grave. Essa foi a origem de D. BRANCA, que fiz seguidamente e sem interrupção, desde Julho até Outubro desse ano de 24, completando-a antes de CAMÕES que primeiro começara, e que só fui acabar a Paris no Inverno de 24 a 25 . E quase que tenho hoje saudades - tal nos tem andado a sorte! - das engelhadas noites de Janeiro e Fevereiro que numa água-furtada da Rua do Coq. St. Honoré passávamos com os pés cozidos no fogo, eu e o meu amigo velho o Sr. J.V. Barreto Feio, ele trabalhando no seu Salústio, eu lidando no meu Camões, ambos proscritos, ambos pobres [...] GARRETT, 1984, p.61)
\end{abstract}

Num outro campo de migração, é interessante notar o caso de Eça de Queirós no qual a ausência do país por períodos prolongados, como embaixador em Cuba, França e Inglaterra implicou a interrupção do seu projeto Cenas da Vida Portuguesa, conjunto de doze novelas planeado como espelho naturalista da sociedade portuguesa; monumento literário que implicaria a observação direta e profunda da sociedade portuguesa. Numa carta enviada a Teófilo Braga, Eça explica o objetivo do conjunto:

\begin{abstract}
A minha ambição seria pintar a Sociedade portuguesa, tal qual a fez o Constitucionalismo desde 1830 - e mostrar-lhe, como num espelho, que triste país eles formam, eles e elas. É o meu fim nas Cenas da Vida Portuguesa. É necessário acutilar o mundo oficial, o mundo sentimental, o mundo literário, o mundo agrícola, o mundo supersticioso - e com todo o respeito pelas instituições que são de origem eterna, destruir as falsas interpretações e falsas realizações que lhes dá uma sociedade podre. (Queirós, 1951, p.52-53)
\end{abstract}

A falta de contacto direto com a sociedade portuguesa, que a ausência do país determinava, impediu de forma determinante o seu desenvolvimento. É de notar que as obras de Eça de Queirós que mais se afastam do realismo literário foram as que foram produzidas 
durante a sua residência no estrangeiro ${ }^{3}$. Uma migração laboral completamente distinta da que experimentaram forçosamente os autores da primeira geração romântica mas que determinou também um contacto menos objetivo e concreto com a realidade portuguesa.

No caso da primeira geração romântica, a ausência de contacto direto com a realidade do país implicou o fortalecimento de um vínculo que se expressou na agudização do sentimento e na recriação idealizante dos símbolos nacionais criando um espaço tocado pelo maravilhoso popular e medieval, pela vontade de, nas palavras de Garrett, documentar e restaurar o grande livro nacional que é o povo. O exílio potenciou, aquilo que o Romantismo já trazia na sua origem, a idealização épica de um povo personificado nos seus símbolos vitais.

\section{Bibliografia}

GARRETT, Almeida. Camões / Dona Branca. Lisboa: Círculo de Leitores, 1984.

. Romanceiro e Cancioneiro Geral Vol. II.. Lisboa. Gabinete de Etnografia: 1963, p. 7. . Viagens na Minha Terra. Lisboa: Círculo de Leitores, 1984.

GEARY, Patrick J., O Mito das Nações: A Invenção do Nacionalismo, Lisboa, Gradiva, 2008.

HERCULANO, Alexandre. Opúsculos, Tomo IX. Rio de Janeiro: Bertrand / Francisco Alves, 1898.

LOPES, Óscar; SARAIVA, António José. História da Literatura Portuguesa. $17^{\mathrm{a}} \mathrm{ed}$. Porto: Porto Editora, 2008.

LOURENÇO, Eduardo. O Romantismo e Camões, in Idioma, 21. Rio de Janeiro: Centro Filológico Clóvis Monteiro - UERJ, 2001. Disponível em http://www.institutodeletras.uerj.br/revidioma/21/idioma21_a10.pdf), p. 75-81, acesso em 02/09/2014.

QUEIRÓS, Eça de. Notas Contemporâneas. Porto: Lello \& Irmão, 1951.

\footnotetext{
${ }^{3} \mathrm{O}$ conto $O$ Mandarim, escrito durante a sua permanência em Inglaterra e publicado em 1880 é desse caso um exemplo concreto
} 